\title{
Gender Identity Disorder is Not Simply Two in One
}

\author{
Syed Masroor A ${ }^{\mathrm{a}}$, Abdul Ghani K \\ ${ }^{a}$ Department of Psychiatry, Kulliyyah of Medicine, International Islamic University Malaysia \\ ${ }^{b}$ Department of Psychiatry, Hospital RIPAS, Brunei Darussalam
}

\begin{abstract}
A Case Report on Gender Identity Disorder with Recurrent Depressive Disorder is presented. Individuals having this disorder often exhibit discomfort about their actual anatomic gender, and they may have wished to alter their bodies. Sex role-stereotypes adopted during childhood are the beliefs, characteristics and behaviors of individual cultures that are considered normal and appropriate for boys and girls to possess. These "norms" are influenced by one's family and friends, the mass-media, and their community. Since some cultures disapprove of cross-gender behavior, it often results in significant problems for affected individuals and those in close relationships with them. The importance of treatment is not only because of the high rate of mental-health problems, including Depression but with higher suicide rate among untreated transsexual people than in the general population. These problems are not usually related to the gender identity issues themselves, but the social and cultural responses to gender-deviated individuals. An example which classically illustrates Gender Identity Disorder is the case of a young man from Brunei Darussalam, who was seen and treated. This contribution will highlight the cultural and religious perspective of this Disorder.
\end{abstract}

KEYWORDS: Gender identity, religion, culture, sexuality, depression

\section{INTRODUCTION}

Psychologists and physicians diagnose gender identity disorder to describe persons who experience significant gender dysphoria. The disorder affects an individual's self-image, and can impact the person's behavior, mannerisms, and dress. These troubles are not usually linked to the gender identity issues themselves, but the societal responses to genderdeviated individuals. Some of them are raised in faiths that condemned their actions as immoral or wrong. ${ }^{1}$ They receive pressure from society. This is one of the important reasons for high rate of mental-health problems, including depression among untreated transsexual people.

Transsexuals are stigmatized in many parts of the world. Discrimination and negative attitudes towards transsexuals often accompany certain religious philosophies or social values. There are cultures that have no difficulty integrating people who change gender roles, sometimes holding them with high regard. However, many cultures strongly disapprove of cross-gender behavior; that results in significant problems for affected persons and those in close relationships with them. ${ }^{2}$

Corresponding author:

Dr. Syed Masroor Ali MCPS (Pakistan)

Assistant Professor, Department of Psychiatry,

Faculty of Medicine, International Islamic University Malaysia

25100 Kuantan, Pahang, Malaysia

Email:dr_hsmali@yahoo.com

Phone: 0060169414920
The prevalence of gender identity disorder in England and Wales is estimated at 1 in 34,000 males and 1 in 108,000 females. ${ }^{3}$ Brunei Darussalam is a small country with a population of 375,000 . The prosperous kingdom is an Islamic state. The majority of Bruneians are the Muslim Malays. There is no single case report is published, although the number of people with Gender Identity Disorder are not uncommon in Brunei Darussalam.

\section{CASE REPORT}

Mr. A was called up, but surprisingly, Miss. B entered into the consulting room. He mentioned that I am the right person. He further clarified that since last year, he has changed his physical appearance by using hormones.

This was his $4^{\text {th }}$ contact to Psychiatric unit. He presented with severe depressive symptoms since few months after knowing that his homosexual partner is having liver cancer.

Mr. A was born 28 years ago as a male. His father is a retired a officer and used to be a very strict person. $\mathrm{He}$ is the $4^{\text {th }}$ among three sisters and two brothers. He belongs to a strict religion observant family. After finishing primary education his father sent him to a religious boarding school to memorize the Holy Quran. He couldn't manage to do it and left that school. With the time, he stopped praying to God and the other religious rituals. Since childhood, he always preferred the company of females and used to involve only in indoor sports. He denied any history of masturbation though used to have fantasies of being a passive partner as homosexual. 
He was referred firstly to a Psychiatrist for evaluation at the age of 13 years with history of depressive symptoms like lack of interest, poor motivation, and low mood with social withdrawal. At this time he did not have any attraction towards the opposite sex and he faced sexual identity disturbances. He was treated with anti depressants together with a psychological treatment for a few weeks, but since he recovered from the depressive symptoms, he discontinued his follow up.

After 7 years, he came again with almost the same depressive symptoms. During this period he finished his diploma and worked as an information technology assistant. All through those days, there was no heterosexual contact, but he admitted that he enjoys in homo sexuality as a passive partner without having any transvestite's behavior. He was still feeling himself as feminine although he was not wearing women's clothes. Anti depressants were prescribed to him but he did not continue the treatment even though the depressive symptoms were not remitted.

After another 5 years, (latest contact) he appeared with the depressive symptoms again. He believed himself a misfit in the society. There was no intention to commit suicide but he had fear of it. This time he started believing himself as a real woman. He went overseas to get some hormonal treatment, which helped him to change his outlook as a female. He couldn't afford to go for sex reassignment surgery, although he wanted to do that as well.

Throughout the period he was investigated for anatomical abnormalities. His hormonal assays were in a normal range and he was ruled out for any organic cause for his sexual preference. He was successfully treated for the depressive illness every time with antidepressants and cognitive behavior therapy. He was informed about the risk and consequences of sex reassignment surgery, and he was told that often after surgery persons realize that they are not happier in their new gender than they were in their birth gender. He showed improvement in the depressive symptoms but considering his transsexual behavior, he was advised for a continuous follow up.

\section{DISCUSSION}

Gender Identity Disorder is not an uncommon problem all over the world. These people again and again exhibit a desire to express themselves in a way that is not socially acceptable for their assigned sex from an early age. ${ }^{4}$ This is sometimes painful and difficult. To avoid exposing any of the inappropriate and taboo signs about themselves, they try to restrict from feeling them, keep themselves away with a gesture, a posture, or anything that would allow others to smell that something about them is not right, that would single them out and make them a target for social justice. They feel difficult at hiding their feelings deeper and farther away. So they remain confused that the transsexuality is learned or genetic.
Eventually, sufferers usually stay in stress when they feel themselves trapped in the wrong body. ${ }^{5}$

The relationship between transgenderism and religion varies widely around the world. Religions range from condemning any gender-variant behavior, to honoring transgender people as religious leaders. Brunei Darussalam is a small Islamic country where the people are closed to each other. The society is influenced by culture and superstitious beliefs. Mental illnesses are stigmatized and still there is lacking about mental health awareness.

In Islam, the term mukhannatun is used to describe gender-variant people, usually male-to-female transsexuals. A mukhannath is the male who carries in his movements, appearance and in language, the characteristics of a woman. There are two types; the first is the one in whom these characteristics are innate; he did not put them on by himself, and therein is no guilt, no blame and no shame, as long as he does not perform any illicit act or exploit it for money like prostitution, etc. The second type acts like a woman out of immoral purposes, and he is the sinner and blameworthy. The status of mukhannathun in Islam has been partially based upon their inability to have penetrative sex with women, whether by inclination or due to anatomic interventions. They were allowed to mix up into families but ejected if they displayed sexual interest in women. ${ }^{6}$

There are many legal issues and aspects of transsexuals. The inability to fit into the male/female box causes many problems. The one most often mentioned is, which bathroom to use. Which section of the mosque to use for prayers? How to address their civil rights and sexual rights? Employment, eligibility to participate in games, vote casting, and heir ship issues, are usually main concern of people with gender identity disorder. ${ }^{6}$ It is unfortunate that most local media depict transsexuals in a negative light. Public view upsets the psychological and emotional state of a transgender, given that most face an unsympathetic atmosphere and consider them as deviant in cultures that are unable to play a constructive role. Working on this paper has helped me acquire a lot and carry on the process of questioning sex and gender.

\section{CONCLUSION}

This critical situation of victims with Gender Identity Disorder, and high rate of mental health problem especially high suicidal risk among untreated transsexuals necessitates further research looking at this serious situation.

\section{REFERENCES}

1. Yousafzai AW, Bhutto N. Gender identity disorder. Is this a potentially fatal condition? J Ayub Med Coll Abbottabad 2007; 19:136-7.

2. Cook E. Exploring transsexual and transgender issues. [online] Available at: Aphroweb.net/ 
papers/trans.htm. Accessed 12 July 2013.

3. Hoenig J, Kenna JC. The prevalence of transsexualism in England and Wales. $\mathrm{Br} \mathrm{J}$ Psychiatry 1974; 124:181-90.

4. Abidi MA, Hafizullah. Gender identity disorder. Journal of College of Physicians and surgeons Pakistan 2001; 11;255-6.

5. Hooper SR, Hynd GW, Mattison RE. Child psychopathology: Diagnostic criteria and clinical assessment. Psychology Press, 2013.

6. Kugle SS. Homosexuality in Islam. Critical reflection on Gay, Lesbian, and Trans gender Muslims. Oxford: One World Publication, 2010: 6; 235. 